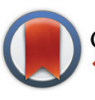

CrossMark \& click for updates

Cite this: Food Funct., 2017, 8, 701

Received 26th September 2016 Accepted 3rd January 2017

DOI: 10.1039/c6fo01411a

rsc.li/food-function

\section{Investigation into the bioavailability of milk protein-derived peptides with dipeptidyl- peptidase IV inhibitory activity using Caco-2 cell monolayers $\uparrow$}

\begin{abstract}
Isabelle M. E. Lacroix, Xiu-Min Chen, David D. Kitts and Eunice C. Y. Li-Chan*
In recent years, peptides derived from a variety of dietary proteins have been reported to exhibit inhibitory activity against the dipeptidyl-peptidase IV (DPP-IV) enzyme, a target in the management of type 2 diabetes. While much attention has been given to the production and identification of peptides with DPP-IV inhibitory activity from food proteins, particularly dairy proteins, little is known on the bioavailability of these molecules. In this study, the stability and transport of five previously identified milk-derived peptides (LKPTPEGDL, LPYPY, IPIQY, IPI and WR) and a whey protein isolate (WPI) digest with DPP-IV-inhibitory activity were investigated using Caco-2 cell monolayers as a model system for human intestinal absorption. Even though a small percentage (ranging from $0.05 \%$ for LPYPY to $0.47 \%$ for WR) of the bioactive peptides added to the apical side was able to cross the monolayer intact, all five peptides investigated were susceptible to peptidase action during the transport study. Conversely, only minor changes to the WPI digest composition were observed. Determination of the DPP-IV inhibitory activity of the peptides and amino acids identified in the apical and basolateral solutions showed that most degradation products were less effective at inhibiting DPP-IV than the peptide they originated from. Findings from this research suggest that the susceptibility of food-derived DPP-IV inhibitory peptides to degradation by intestinal brush border membrane enzymes may alter their biological activity in vivo. Further research should be conducted to enhance the bioavailability of DPP-IV inhibitory peptides.
\end{abstract}

\section{Introduction}

Inhibitors of the enzyme dipeptidyl-peptidase IV (DPP-IV) are non-insulin anti-diabetic agents currently available for the treatment of type 2 diabetes. Often referred to as 'gliptins', these oral medications help maintain glycemic targets by preventing the rapid breakdown by DPP-IV of gastrointestinal incretin hormones that play a pivotal role in the regulation of blood glucose levels. ${ }^{1}$ Generally well accepted, safe in renal impaired individuals and weight neutral, DPP-IV inhibitors have attracted considerable attention, and since the launch of the first gliptin in 2006, at least ten other DPP-IV inhibitors have now been approved in several countries as both monotherapy and add-on combination therapy. ${ }^{2}$

More recently, food-derived constituents, primarily peptides, have also been found to inhibit the activity of the DPP-IV

The University of British Columbia, Faculty of Land \& Food Systems, Food Nutrition \& Health Program, 2205 East Mall, Vancouver, BC, Canada V6T $1 Z 4$.

E-mail: Eunice.Li-Chan@ubc.ca; Fax: +1-604-822-5143; Tel: +1-604-822-6182

$\dagger$ Electronic supplementary information (ESI) available. See DOI: 10.1039/ c6fo01411a enzyme in vitro and in animal models. ${ }^{3,4}$ The discovery that dietary proteins can be used to produce natural DPP-IV inhibitors has generated great interest in their potential to help improve glycemic regulation and as a result, considerable research efforts have been put toward the production, identification and characterization of DPP-IV inhibitory peptides. To date, proteins from more than 15 food commodities have been reported as sources of peptides with DPP-IV inhibitory activity. Among these, those from milk have been the most extensively studied and many of the more than 150 known DPP-IV inhibitory peptides that have been reported can be found in the sequence of casein and whey proteins. ${ }^{3}$

While the production of DPP-IV inhibitors from dietary proteins and the identification of active peptide sequences have been the subject of a large body of research, little is currently known on the bioavailability of these bioactive molecules. In order to prevent the breakdown of the incretin hormones, DPP-IV inhibitory peptides need to be transported across the lumen and to reach the endothelium of the capillary bed within the intestinal wall where DPP-IV can be found in close proximity to the cells secreting the incretins., ${ }^{5,6}$ Although studies on the absorption of peptides and proteins have shown 
that dipeptides and tripeptides can cross the intestinal endothelium and reach the systemic circulation intact, the absorption of oligopeptides and proteins through the lumen is believed to be much more limited. ${ }^{7}$ In order to reach the blood stream intact, bioactive peptides must not only be transported across the intestinal wall, but also be resistant to hydrolysis by peptidases present in the brush border membrane. To the authors' knowledge, the intestinal transport of peptides with DPP-IV inhibitory activity has never been studied.

The objectives of this research were, therefore, to investigate the stability to intestinal epithelium brush border peptidases and the cellular transport of milk-derived peptides with previously established in vitro DPP-IV inhibitory activity using the human epithelial colorectal adenocarcinoma Caco-2 cell line as a model system for intestinal epithelial permeability.

\section{Experimental}

\section{Materials}

Caco-2 cells (HTB-37 ${ }^{\mathrm{TM}}$ ) were purchased at passage 18 from the American Type Culture Collection (ATCC, Manassas, VA, USA). Pepsin (from porcine gastric mucosa, $\geq 2500$ units per mg protein), pancreatin (from porcine pancreas, $8 \times$ USP specifications), amino acids (L-leucine, L-proline, L-tyrosine, L-glutamine, L-isoleucine, L-tryptophan, L-arginine; purity $\geq 98 \%$ ), Eagle's Minimum Essential Medium (EMEM), penicillin-streptomycin solution (10000 units penicillin and $10 \mathrm{mg}$ streptomycin per mL), Dulbecco's Phosphate Buffered Saline (PBS), Hank's Balanced Salt Solution (HBSS), Lucifer yellow $\mathrm{CH}$ dilithium salt, diprotin A, and 3-(4,5-dimethyl-2-thiazolyl)2,5-diphenyl- $\mathrm{H}$-tetrazolium bromide (MTT) were obtained from Sigma-Aldrich (St Louis, MO, USA). Trypsin-EDTA (0.25\%) and fetal bovine serum (FBS) were from Gibco ${ }^{\mathrm{TM}}$ (Thermo Fisher Scientific, Mississauga, ON, Canada). The whey protein isolate (WPI 895, Fonterra, New Zealand; 92\% protein) was donated by Caldic Canada Inc. (Delta, BC, Canada). The synthesized peptides ( $\geq 98 \%$ purity) were prepared and purified by GL Biochem (Shanghai) Ltd (Shanghai, China).

\section{In vitro digestion}

The whey protein isolate was subjected to in vitro digestion as described by Lacroix and Li-Chan. ${ }^{8}$ Briefly, a WPI solution (3\% w/v protein in deionized distilled (dd) $\mathrm{H}_{2} \mathrm{O}$ ) was adjusted to pH 2.0 using $6 \mathrm{~N} \mathrm{HCl}$ and pre-incubated to $37^{\circ} \mathrm{C}$ in a water bath shaker (New Brunswick Scientific, Enfield, CT, USA). Pepsin (4\% enzyme/substrate $(\mathrm{E} / \mathrm{S})$ ratio on a w/w basis) was then added and the solution was incubated at $37^{\circ} \mathrm{C}$ for 1 hour, after which the $\mathrm{pH}$ was adjusted to 5.3 using $0.9 \mathrm{M} \mathrm{NaHCO}_{3}$. Pancreatin $(\mathrm{E} / \mathrm{S}=4 \%)$ was added and after further adjustment of the $\mathrm{pH}$ to 7.5 with $1 \mathrm{~N} \mathrm{NaOH}$, the solution was incubated at $37{ }^{\circ} \mathrm{C}$ for 2 hours. The digested WPI was heated at $85^{\circ} \mathrm{C}$ for $10 \mathrm{~min}$ to inactivate the enzyme and centrifuged using a Sorvall Legend X1R centrifuge (Thermo Scientific, Osterode am Harz, Germany) for $10 \mathrm{~min}$ at $12100 \mathrm{~g}$. The supernatant was collected, desalted using a Micro Acilyzer S1 desktop electrodialyzer with
AC-110-20 cartridges (Aston Corporation, Japan) and freezedried (Labconco Corporation, Kansas City, MO, USA).

\section{Caco-2 cell culture}

Caco-2 cells obtained from the American Type Culture Collection were grown on tissue culture flasks in EMEM supplemented with $10 \%$ fetal bovine serum, $100 \mathrm{U} \mathrm{mL}^{-1}$ of penicillin and $100 \mu \mathrm{g} \mathrm{mL} \mathrm{m}^{-1}$ of streptomycin. The cells were maintained at $37{ }^{\circ} \mathrm{C}$ under an atmosphere containing $5 \% \mathrm{CO}_{2}$. The medium was changed every 2-3 days, and the cells were subcultured weekly by trypsin-EDTA treatment. Following confluence, the cells were seeded in 24-well high pore density polyethylene terephthalate inserts purchased from Corning $\left(0.4 \mu \mathrm{m}\right.$ pore size, $100 \pm 10 \times 10^{6} \mathrm{~cm}^{-2}$ pore density, $0.3 \mathrm{~cm}^{2}$ grown surface) (VWR, Mississauga, ON, Canada), at a density of $2.5 \times 10^{5}$ cells per $\mathrm{cm}^{2}$. The culture medium was replaced every 2-3 days and the cells were grown for 20-21 days. All the cells used in this study were between 22 and 29 passages. The monolayer integrity was monitored by measuring transepithelial electrical resistance (TEER) using a Millicell® ERS-2 voltohmmeter (EMD Millipore, Darmstadt, Germany) and only those having TEER values higher than $200 \Omega \mathrm{cm}^{2}$ were used.

\section{Cytotoxicity assay}

Milk protein-derived peptides LKPTPEGDL, IPIQY, LPYPY, WR, IPI and WPI digest with known in vitro DPP-IV inhibitory activity $^{8,9}$ were assessed for cytotoxicity using the MTT assay. ${ }^{10}$ The peptides and WPI digest were first dissolved in HBSS, then further diluted in complete EMEM to concentrations ranging from 1 to $6 \mathrm{mM}$ and 5 to $20 \mathrm{mg} \mathrm{mL}^{-1}$, respectively, and the $\mathrm{pH}$ was adjusted to neutrality using either $1 \mathrm{~N} \mathrm{NaOH}$ or $1 \mathrm{~N} \mathrm{HCl}$. The samples $(100 \mu \mathrm{L})$ were added to Caco- 2 cells seeded in 96-well culture plates (density of $1 \times 10^{5}$ cells per $\mathrm{cm}^{2}$ ) and grown for 21 days. The plates were incubated at $37^{\circ} \mathrm{C}$ under an atmosphere containing $5 \% \mathrm{CO}_{2}$ for 24 hours after which the tested samples were removed and $100 \mu \mathrm{L}$ of MTT $\left(0.5 \mathrm{mg} \mathrm{mL} \mathrm{mL}^{-1}\right.$ in complete EMEM) was added to the cells. Following 4 hours of incubation in the dark, $100 \mu \mathrm{L}$ of $10 \%$ SDS in $0.01 \mathrm{~N} \mathrm{HCl}$ was added and the plates were further incubated at $37^{\circ} \mathrm{C}$ overnight. The absorbance of the released formazan was measured at $570 \mathrm{~nm}$ using a Multiskan Spectrum microplate spectrophotometer (Thermo Labsystems, Chantilly, VA, USA). The viability of the treated cells was expressed as a percentage of the control cells that were not exposed to the samples.

\section{Transport study}

Caco-2 cells grown in EMEM for 20-21 days as described above were used to study the cellular transport of the peptides (LKPTPEGDL, IPIQY, LPYPY, WR, IPI) and the WPI digest. Cells were first washed twice with HBSS and equilibrated in this buffer for $60 \mathrm{~min}$ at $37{ }^{\circ} \mathrm{C}$ prior to the transport experiment. The test samples $(300 \mu \mathrm{L}$ in HBSS, pH adjusted to neutrality using $1 \mathrm{~N} \mathrm{NaOH}$ or $1 \mathrm{~N} \mathrm{HCl})$ and HBSS $(700 \mu \mathrm{L})$ were added to the apical (insert) and basolateral (well) sides of the monolayers, respectively, and the plates were incubated for 2 hours at $37^{\circ} \mathrm{C}$ under an atmosphere containing $5 \% \mathrm{CO}_{2}$. The apical and 
basolateral solutions were then collected, their contents analyzed by RP-HPLC as described in the following section, and the basolateral samples freeze-dried. The TEER values and the permeability of Lucifer yellow were measured before and after the experiment. The cellular permeability of each sample was tested at least in quadruplicate, and transport across the monolayers was reported as the mean value expressed as a percentage of the samples added to the apical side.

\section{Reversed-phase high-performance liquid chromatography (RP-HPLC) analysis}

The five peptides and the WPI digest, as well as the apical and basolateral solutions obtained from the transport study, were analyzed by RP-HPLC using an Agilent 1260 Infinity HPLC system (Agilent Technology, Mississauga, ON, Canada). The peptides or digest $(10 \mu \mathrm{L})$, apical $(10 \mu \mathrm{L})$ and basolateral $(50 \mu \mathrm{L})$ samples were injected into a Phenomenex Jupiter ${ }^{\mathrm{TM}}$ C12 Proteo $90 \AA$ APLC column $(250 \mathrm{~mm} \times 4.6 \mathrm{~mm}, 4 \mu \mathrm{m}$; Phenomenex®, Torrance, CA, USA) at $40^{\circ} \mathrm{C}$. The samples were eluted using a linear gradient of acetonitrile (0-60\% (v/v) in $30 \mathrm{~min})$ and $0.1 \%$ TFA $(\mathrm{v} / \mathrm{v})$ in $\mathrm{H}_{2} \mathrm{O}$ at a flow rate of

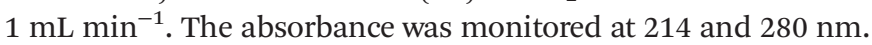

Peak areas were determined to estimate the percent permeability of the original test peptides as well as the overall amount of the original peptide plus degradation products transported through the monolayers.

In addition to the five peptides studied for the cellular transport, 16 tetra-, tri- and dipeptides derived from the peptide sequences IPIQY, LPYPY, IPI and WR, as well as the constituent amino acids, were analyzed by RP-HPLC in order to identify the amino acids and peptides present as breakdown products in the basolateral and apical solutions. The peptides and amino acids were solubilized in HBSS ( $1 \mathrm{mM}$ to $10 \mathrm{mM}$ ), analyzed by RP-HPLC as described above and their elution time was compared with that of the peaks observed in the elution profiles of the apical and basolateral solutions obtained during the transport study.

\section{Determination of the DPP-IV inhibitory activity}

The synthesized peptides, amino acids as well as the apical and basolateral solutions were tested for their effect on DPP-IV activity using the chromogenic substrate Gly-Pro- $p$-NA as previously described by Lacroix and Li-Chan. ${ }^{11}$

A positive control corresponding to the activity of DPP-IV in the absence of an inhibitor was prepared using $100 \mathrm{mM}$ Tris$\mathrm{HCl}$ buffer in place of the sample, while a negative control corresponding to the absence of DPP-IV activity was prepared using $100 \mathrm{mM}$ Tris-HCl buffer in place of both the sample and enzyme solution. HBSS instead of Tris-HCl buffer was used to prepare the positive and negative controls for assaying the apical and basolateral solutions.

The concentration of the sample used to test the DPP-IV inhibitory activity of the apical and basolateral solutions was based on the amount of the peptide material present in the basolateral compartment, as determined by RP-HPLC.

\section{Statistical analysis}

All assays were conducted at least in triplicate, and significant differences were established at $P<0.05$ by performing one-way analysis of variance using the general linear model and pairwise comparison with Tukey's method (Minitab Statistical Software Version 16, Minitab Inc., State College, PA, USA).

\section{Results}

Cytotoxicity of individual milk protein-containing peptides and WPI digest

The effect of the milk protein-derived peptides and WPI digest on the viability of the Caco-2 cells was first determined using the MTT assay. As shown in Fig. 1, the samples had no cytotoxic effect at the concentrations used. Transport experiments of LKPTPEGDL, LPYPY, IPIQY and WR and the WPI digest were therefore performed using sample concentrations of $6 \mathrm{mM}$ and $20 \mathrm{mg} \mathrm{mL}^{-1}$, respectively. The transport of the wellknown and potent DPP-IV inhibitor diprotin A (IPI) was also investigated for comparison using a concentration of $1 \mathrm{mM}$.

\section{Resistance of the peptides and WPI digest to Caco- 2 cell peptidases}

The resistance of the peptides and WPI digest to proteolytic degradation by Caco-2 cell enzymes was assessed by RP-HPLC analysis of the apical solutions obtained before (Fig. 2A) and after (Fig. 2B) 2-hour incubation of the samples applied to the

A

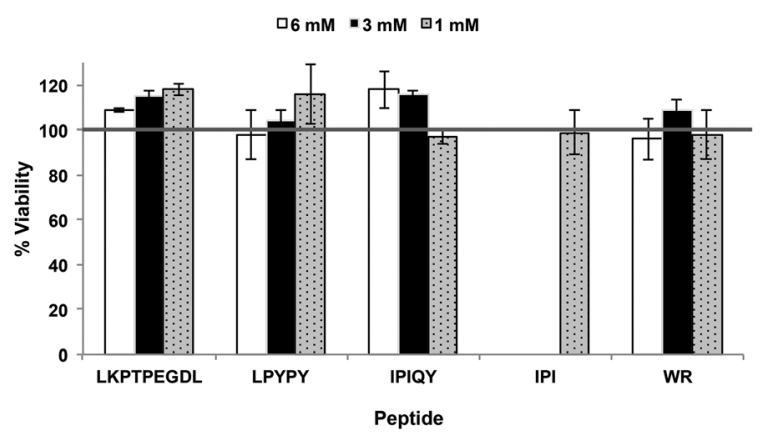

B

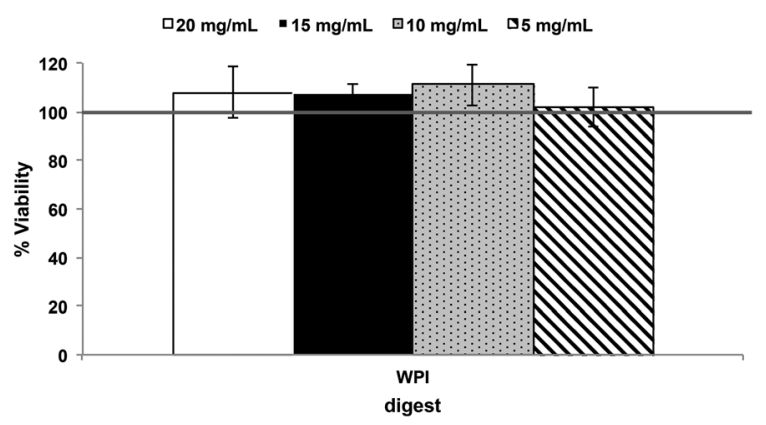

Fig. 1 Viability (\%) of Caco-2 cells after exposure for 24 hours to the milk protein-derived peptides (A) and the whey protein isolate (WPI) digest (B). Each bar represents the mean and standard deviation of at least three determinations. 

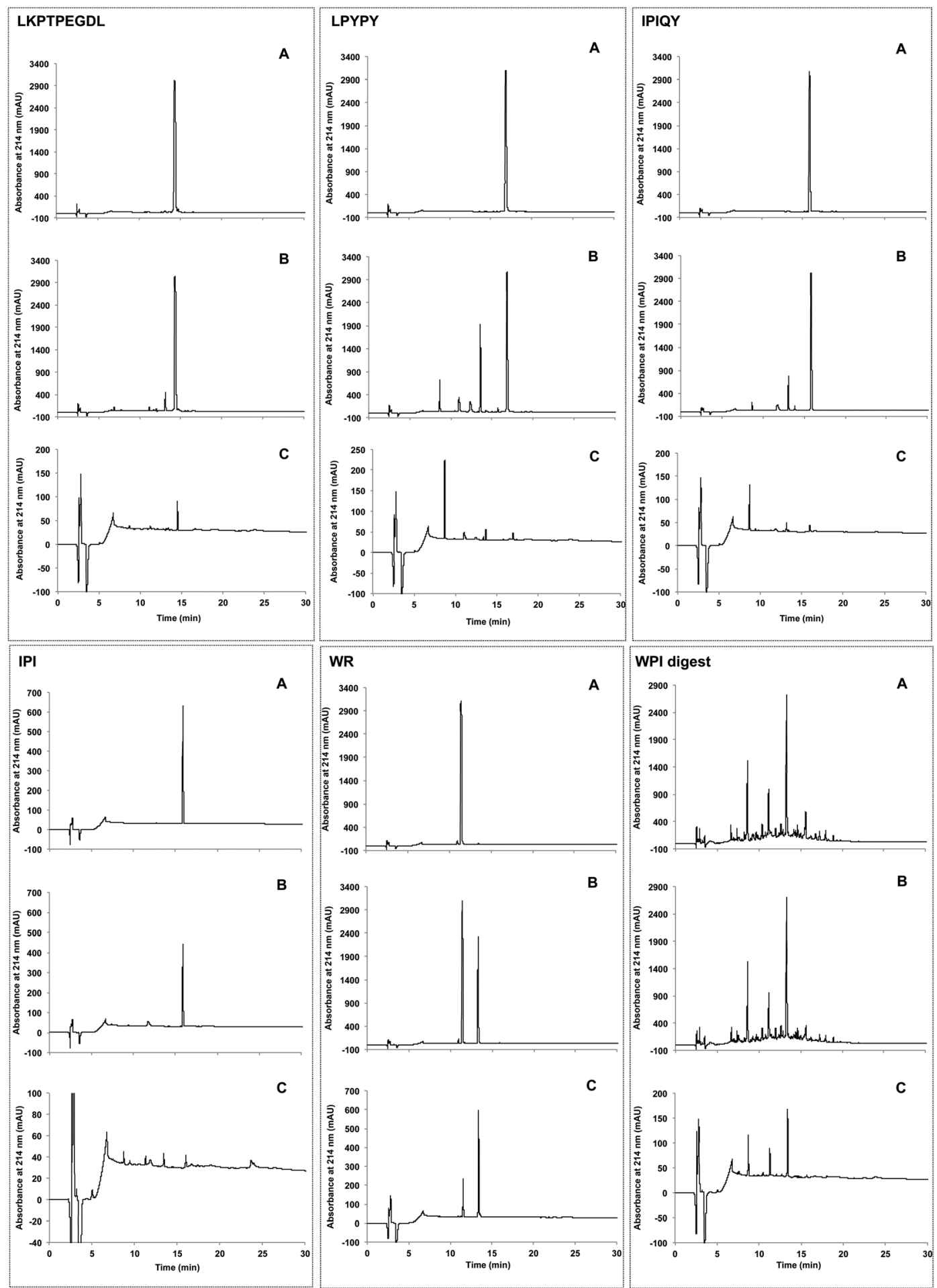

Fig. 2 Elution profiles obtained by RP-HPLC of the milk protein-derived peptides and the whey protein isolate (WPI) digest added to the apical compartment (A) and the resulting apical (B) and basolateral (C) solutions collected after incubation for 2 hours.

apical side of the monolayers. All five peptides were degraded by peptidases present on the Caco-2 cell surface, as shown by the appearance of additional peaks in the apical solutions collected after the incubation period. Of the five peptides studied, IPI was the most susceptible to enzymatic hydrolysis, approxi- mately $30 \%$ of the original peptide added to the apical chamber having been broken down after 2 hours (Fig. 3).

In comparison to the individual peptides, the WPI digest was found to be less susceptible to hydrolysis by the brush border membrane peptidases, only a few minor additional 


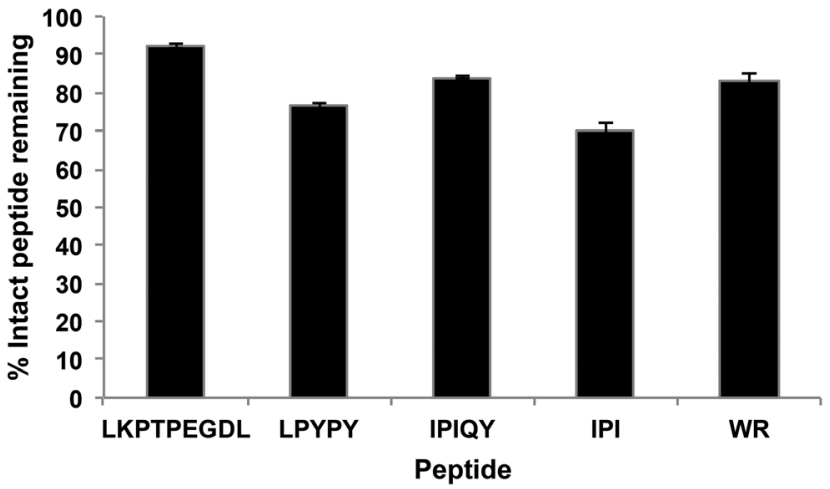

Fig. 3 Percentage of intact peptides remaining in the apical compartment after $2 \mathrm{~h}$ incubation. Each bar represents the mean and standard deviation of at least four replicates.

peaks being detected in the apical solution collected after the incubation period (Fig. 2A and B).

\section{Apical to basolateral transport}

Transport of the peptides and WPI digest from the apical to the basolateral side of the Caco-2 cell monolayer was determined by RP-HPLC analysis of the basolateral solutions collected after the 2-hour transport study. The chromatograms of the basolateral solutions (Fig. 2C) show peaks with retention times corresponding to the intact peptides and hydrolysis products observed in the apical layers (Fig. 2A and B), indicating that both the intact peptides as well as some of their metabolites were found to be transported across the Caco-2 cell monolayers. Based on the peak areas, only a small percentage of the original peptides added to the apical side were transported intact across the cell monolayers, with WR showing the highest percent transport (0.47\%) (Fig. 4). The dipeptide WR was also found to have the greatest overall (intact peptide and

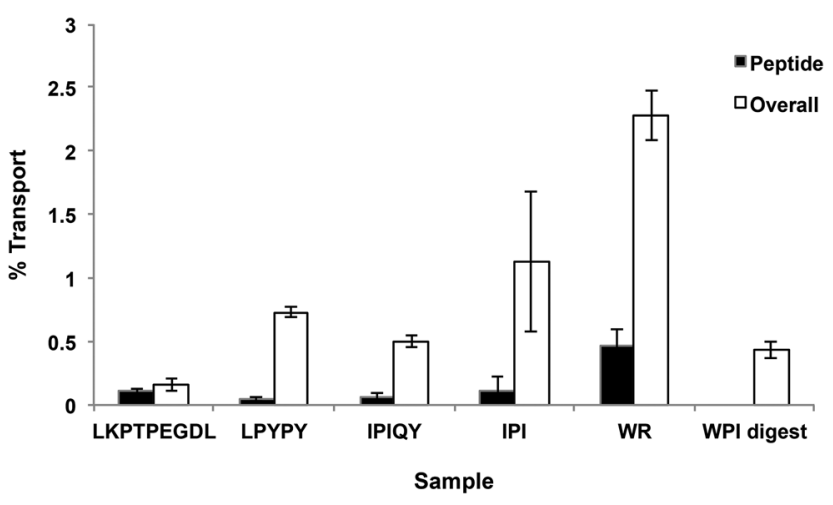

Fig. 4 Transport of milk protein-derived peptides and the whey protein isolate (WPI) digest through Caco-2 cells. The percent transport of the peptides and of the peptides and degradation products (overall) across the monolayer was calculated from the peak areas observed in the RP-HPLC chromatograms of the samples added to the apical compartment and of the basolateral solutions collected after incubation for 2 hours. Each bar represents the mean and standard deviation of at least four replicates. degradation products) percent transport $(2.2 \%)$ of all the samples tested. Similarly to the synthesized peptides, only a limited amount $(0.43 \%)$ of the peptides present in the WPI digest and their degradation products were carried across the Caco-2 cell monolayers (Fig. 4).

\section{DPP-IV inhibitory activity of apical and basolateral solutions}

The apical and basolateral solutions obtained at the end of the 2-hour transport study were tested for their in vitro effect on DPP-IV activity and compared to that of the peptides added to the apical side of the Caco-2 cell monolayers. With the exception of WR, all peptide solutions collected in the apical compartments after the 2 hours of incubation period displayed lower DPP-IV inhibitory activity than at time 0 when just added to the monolayers. Moreover, the basolateral solutions of all five peptides investigated showed a weaker effect on DPP-IV activity than their corresponding apical solutions (Table 1).

In the case of the WPI digest, the effect of the apical and basolateral solutions on the activity of DPP-IV did not differ significantly from the original sample (Table 1). However, the inhibitory activity was weak.

Identification of the constituents in the apical and basolateral solutions and evaluation of the DPP-IV inhibitory activity of the possible breakdown products

In order to identify the amino acids and peptides present in the apical and basolateral compartments following the transport study, all possible breakdown products of the peptides IPIQY, LPYPY, IPI and WR were chemically synthesized and analyzed by RP-HPLC. Their retention times were then matched to those of the peaks observed in the apical and basolateral solutions (Fig. 2B and C, Table S1 $†$ ). This analysis was not performed for the peptide LKPTPEGDL and the WPI digest due to the large number of the possible breakdown products of the nona-peptide and the unknown composition of the

Table 1 DPP-IV inhibitory activity of the peptides and whey protein isolate (WPI) digest prior to the transport study and of the apical and basolateral solutions collected after 2 hours of their application to Caco- 2 cell monolayers

\begin{tabular}{lllll}
\hline & & \multicolumn{2}{l}{$\%$ DPP-IV inhibition } \\
\cline { 3 - 5 } Sample & Concentration $^{b}$ & $\begin{array}{l}\text { Apical } \\
(0 \mathrm{~min})\end{array}$ & $\begin{array}{l}\text { Apical } \\
(120 \mathrm{~min})\end{array}$ & $\begin{array}{l}\text { Basolateral } \\
(120 \mathrm{~min})\end{array}$ \\
\hline LKPTPEGDL & 12.5 & $26 \pm 2 \mathrm{a}$ & $22 \pm 0 \mathrm{~b}$ & $18 \pm 2 \mathrm{c}$ \\
LPYPY & 75 & $25 \pm 2 \mathrm{a}$ & $20 \pm 1 \mathrm{~b}$ & $12 \pm 4 \mathrm{c}$ \\
IPIQY & 50 & $42 \pm 3 \mathrm{a}$ & $34 \pm 1 \mathrm{~b}$ & $15 \pm 3 \mathrm{c}$ \\
IPI & 12.5 & $49 \pm 3 \mathrm{a}$ & $38 \pm 2 \mathrm{~b}$ & $14 \pm 5 \mathrm{c}$ \\
WR & 75 & $77 \pm 1 \mathrm{a}$ & $72 \pm 1 \mathrm{a}$ & $46 \pm 8 \mathrm{~b}$ \\
WPI digest & 62.5 & $15 \pm 1 \mathrm{a}$ & $11 \pm 3 \mathrm{a}$ & $12 \pm 3 \mathrm{a}$
\end{tabular}

${ }^{a}$ Values are expressed as the final assay concentrations of the peptides $(\mu \mathrm{M})$ and WPI digest $\left(\mu \mathrm{g} \mathrm{mL} \mathrm{m}^{-1}\right)$ used to determine the DPP-IV inhibitory activity; the concentrations were chosen based on the amount of peptide material found in the basolateral compartment. ${ }^{b}$ The percent DPP-IV inhibition values are reported as the mean and standard deviation from quadruplicate determination. Within the same row, values with different lowercase letters are significantly different $(P<0.05)$. 
digest, respectively. It should be noted that it was not possible, under the conditions used, to determine by RP-HPLC analysis the presence of the amino acids proline, glutamine and arginine in the apical and basolateral solutions due to their lack of retention on the reversed phase column.

Fig. 5A shows that seven (PYPY, PYP, YPY, LP, PY, YP, Y) of the 11 peptides and amino acids that could theoretically be generated from LPYPY were identified in the apical solution collected after the 2-hour transport study. Of these, YPY, LP, YP and Y were also identified in the basolateral solution. Assessment of the DPP-IV inhibitory activity of the breakdown products revealed that all were less effective at inhibiting the enzyme than the penta-peptide they originated from. Among the LPYPY-derived components identified in the apical and basolateral solutions, the greatest effect was shown by the dipeptide YP (33 and 52\% DPP-IV inhibition for YP and LPYPY, respectively).

The IPIQY-derived peptides IPIQ, IPI, IQY, IP, PI and the amino acid $Y$ were identified in the apical side of the monolayer, and all but IPIQ were also found in the basolateral solution (Fig. 5B). Exhibiting 95\% DPP-IV inhibition, IPI was the most potent constituent determined in the apical and basolateral compartments. This tripeptide was also the only identified breakdown product more effective at inhibiting the DPP-IV enzyme than the parent peptide IPIQY. The inhibitory activity of the other IPIQY-derived molecules found in the apical and basolateral solutions ranged from 8 to $82 \%$ and 8 to $46 \%$, respectively.

With the exception of the amino acid proline, all possible breakdown products of IPI were observed in the apical and baso- lateral solutions. While the dipeptide IP was effective at reducing the activity of the enzyme (46\% inhibition), the peptide PI and amino acids proline and isoleucine only displayed a marginal effect on DPP-IV activity (Fig. 5C). Similarly, even though the peptide WR was a potent DPP-IV inhibitor, its constituent amino acids $\mathrm{W}$ and $\mathrm{R}$ had no significant effect on DPP-IV activity. Both $\mathrm{WR}$ and $\mathrm{W}$ were identified in the apical and basolateral solutions collected after the transport study (Fig. 5D).

\section{Discussion}

Most therapeutic food-derived peptides, including peptides with DPP-IV inhibitory activity, must reach the systemic circulation in order to exert their bioactivity. Hence, the bioavailability of these molecules is a key factor to consider in determining their practical application. Caco-2 cells, being similar to mature human enterocytes after differentiation, have been widely used as a model system to study intestinal absorption of a number of molecules, including bioactive peptides derived from milk proteins. ${ }^{12,13}$

All five peptides investigated in this study were susceptible to Caco- 2 cell peptidases; between 8 and $30 \%$ of the samples added to the apical compartment were hydrolyzed after 2 hours (Fig. 3). At least eight membrane peptidases have been reported to be expressed on the surface of Caco-2 cells. Among these, DPP-IV is believed to be the most active, particularly once the cells are completely differentiated. ${ }^{14}$ Ubiquitously distributed, DPP-IV is known to preferentially act on substrates having a proline or other small uncharged residues such as
A

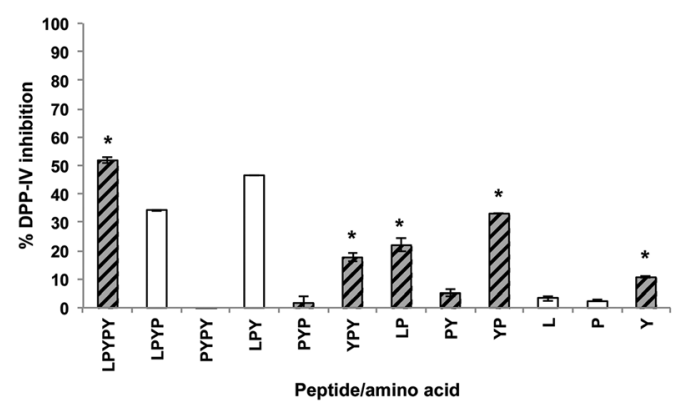

C

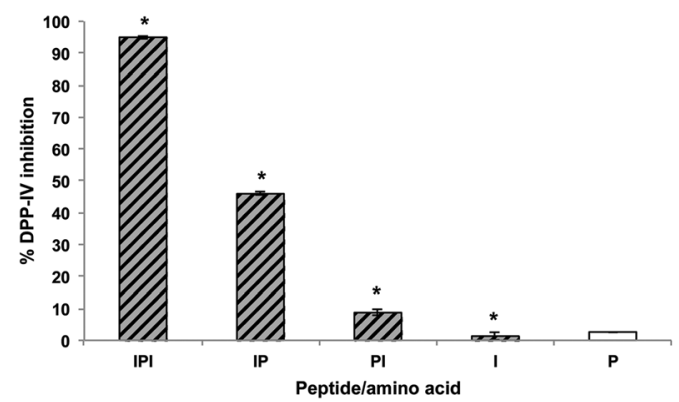

B

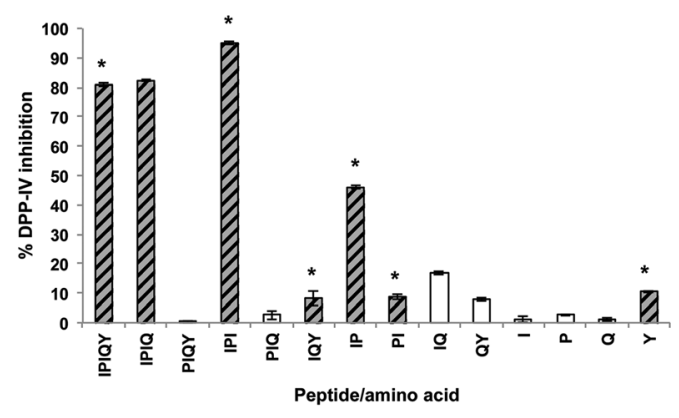

D

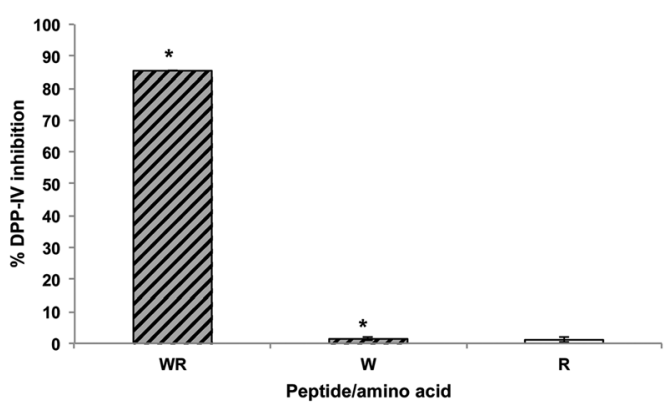

Fig. 5 DPP-IV inhibitory activity of amino acids and peptides derived from LPYPY (A), IPIQY (B), IPI (C) and WR (D). The percent inhibition of DPP-IV activity was measured using $125 \mu \mathrm{M}$ of peptide (final assay concentration). Hatched grey bars and stars represent amino acids or peptides identified in the apical and basolateral solutions, respectively. Under the conditions used, the amino acids P, Q and R were not retained in the RP-HPLC column and therefore their presence in the apical and basolateral solutions could not be determined. 
alanine and serine at their penultimate amino acid position. ${ }^{15}$ The tripeptide IPI, also known as diprotin A, is a well-studied DPP-IV inhibitor that has been shown to be in fact a substrate for the enzyme with a low turnover rate. ${ }^{16}$ Similarly to IPI, the peptides LPYPY and IPIQY possess a proline residue at their $\mathrm{P}_{1}$ position and have been reported to act as competitive inhibitors against DPP-IV, a competitive behavior that has been suggested to be a kinetic artifact resulting from their substrate-mimicking structure. Hence, it is likely that the DPP-IV enzyme on the apical surface, along with other peptidases expressed by the Caco-2 cells, contributed to the observed breakdown of IPI, LPYPY and IPIQY.

The hydrolysis by DPP-IV of milk-protein derived peptides, including IPI, LPYPY and IPIQY, has also been reported in a study by Nongonierma and FitzGerald ${ }^{17}$ in which the authors incubated proline-containing peptides with porcine DPP-IV for 18 hours. Although DPP-IV has a high affinity for peptides having a proline amino acid at their second position, it is unable to hydrolyze those like LKPTPEGDL that bear this residue at their third position. Of the five peptides investigated, LKPTPEGDL was the most resistant to Caco-2 cell peptidases, only $8 \%$ of the peptide applied to the apical side of the monolayer was hydrolyzed at the end of the 2-hour transport study. The dipeptide WR has been previously reported to inhibit DPP-IV in an uncompetitive manner, ${ }^{9}$ and therefore, may also be expected to resist the DPP-IV proteolytic action. The presence of a peak associated with the amino acid tryptophan in the apical and basolateral solutions, however, indicates the susceptibility of WR to other brush border membrane peptidases.

Even though DPP-IV inhibitory peptides may exert their action on the enzyme present on the surface of the intestinal epithelium, to prevent the degradation of the incretin hormones, and consequently improve glycemic regulation, they, or their degradation products, must reach the endothelium of the capillary bed within the intestinal wall where DPP-IV is present in near proximity to the cells secreting the incretins. ${ }^{5,6}$ Of the five peptides investigated, WR had the highest permeability across the Caco- 2 cell monolayer, likely due to its small size. On the other hand, the nona-peptide LKPTPEGDL was found to have the lowest overall percent transport. Studies on the intestinal transport of bioactive peptides conducted over the years have shown evidence of the intestinal uptake of intact di- and tripeptides, as well as some larger peptides, such as lunasin, a 43-amino acid peptide with anti-inflammatory and anti-cancer properties, ${ }^{18}$ and the anti-hypertensive sequences RVPSL ${ }^{19}$ and QIGLF. $^{20}$ However, it is generally believed that most oligopeptides have very low permeability and are not intestinally absorbed in their intact form. The transport of oligopeptides across the intestinal epithelium has been shown to occur via either transcytosis or a paracellular route $^{19}$ and to be influenced by the peptides' structural features such as size, hydrophobicity and molecular surface properties. ${ }^{21}$ Currently, the mechanism(s) by which milk-derived DPP-IV inhibitory peptides cross the lumen is unknown and warrants further investigation.
The hydrolysis of the individual milk protein-derived peptides by brush border membrane peptidases resulted in peptide mixtures with lower DPP-IV inhibitory activity than the original intact peptides (Table 1). This reduction can be explained by the fact that, with the exception of the peptides IPIQ and IPI generated from the cleavage of IPIQY, all degradation products identified in the apical and basolateral compartments exhibited a weaker effect on DPP-IV activity than their corresponding precursor peptides. As only a small portion of the original peptides was transported intact across the Caco-2 cell monolayer, the DPP-IV inhibitory activity of the peptide solutions collected in the basolateral chambers was greatly reduced compared to that of the apical solutions.

Peptides with potent DPP-IV inhibitory activity have been suggested to generally contain a branched-chain amino acid or an aromatic residue with a polar group in the side-chain (primarily tryptophan) at their $\mathrm{N}$-terminal and/or a residue proline at their $P_{1}$ position. The most potent peptides that can be generated from LPYPY (LPYP, LPY, YP), IPIQY (IPIQ, IPI, IP) and IPI (IP) all contain the amino acid proline at their second position.

With the exception of the amino acid tyrosine, which displayed weak DPP-IV inhibitory activity at the concentration tested, none of the other amino acids present in the precursor peptide sequences had a significant effect on DPP-IV activity. The amino acids tryptophan and leucine have both previously been reported in a study by Nongonierma $e t ~ a l .{ }^{22}$ to exhibit a competitive mode of action against the DPP-IV enzyme. However, the potency of the residues determined by the authors was very low $\left(\mathrm{IC}_{50}\right.$ values of 4280.40 and $3419.25 \mu \mathrm{M}$, for $\mathrm{W}$ and L, respectively) which may explain why no inhibitory effect was detected for these amino acids in this study.

Conversely to the individual peptides, the composition profile and DPP-IV inhibitory activity of the WPI digest did not appear to be altered significantly by the enzymatic action of the brush border membrane peptidases. However, with the complex composition of the digest, it is possible that many peptides were simultaneously being hydrolyzed by the Caco-2 cell peptidases, which would not be easily detected in the RP-HPLC chromatograms. Similarly, in a study on the transepithelial transport of whey- and casein-derived peptides, Picariello et al. ${ }^{13}$ did not observe significant differences between the Matrix-Assisted Laser Desorption/Ionization Timeof-Flight Mass Spectrometry (MALDI-TOF MS) profiles of the apical and basolateral solutions. Consistent with the insignificant changes to its composition profile, the DPP-IV inhibitory activity of the digest did not appear to be markedly affected by the enzymatic action of the Caco-2 cell peptidases. The digest being composed of a mixture of peptides, many of which may not be active, it is possible that the changes to individual peptides by the Caco-2 cell peptidases may not significantly affect the overall DPP-IV inhibitory activity of the digest as the newly generated peptides would be expected to also possess various degrees of effectiveness against the DPP-IV enzyme. Moreover, it is important to note that the inhibitory activity of the apical and basolateral solutions was weak at the concentration 
$\left(62.5 \mu \mathrm{g} \mathrm{mL} \mathrm{m}^{-1}\right)$ used to perform the assay and therefore differences between the samples are more difficult to quantify.

The consumption of specific food products, including dairy proteins, has been reported in a number of epidemiological and observational studies to be associated with a reduced incidence of type 2 diabetes. ${ }^{23}$ Although it has been hypothesized that the antidiabetic effect of proteins results from the ability of the bioactive peptides derived from them to inhibit enzymes involved in blood glucose metabolism and/or to stimulate the secretion of gut-derived hormones, these in vivo effects are yet to be validated. The discovery that dietary proteins can be precursors of peptides with DPP-IV inhibitory activity has recently captured the attention of the scientific community. While the production and identification of DPP-IV inhibitory peptides from food proteins has been the object of numerous studies, the bioavailability of these molecules has been mostly overlooked. Both the susceptibility of bioactive peptides to degradation by gastrointestinal peptidases and their limited absorption can greatly impede their potential as functional food ingredients. Therefore, in order to really evaluate their biological potential, it is critical to conduct research considering these aspects, for example, using brush border membrane vesicles to simulate the human intestinal digestion, or Caco- 2 cell monolayers to assay the stability against intestinal peptidases and the ability to translocate across the epithelium. ${ }^{24}$ In fact, the present findings using the Caco- 2 cell model system suggest that not all of the peptides reported in the literature to have the ability to inhibit DPP-IV activity in vitro may be resistant to gastrointestinal peptidases and/or be transported across the lumen in significant amounts to confer a meaningful action on the enzyme in vivo. Additional research on the bioavailability and in vivo efficacy of bioactive peptides is needed to ascertain their role in blood glucose regulation.

The development of nano-delivery systems has attracted much research attention in recent years as a way to preserve the therapeutic functionality of bioactive molecules by conferring resistance to degradation as well as enhancing cellular transport. $^{25}$ To date, most research in this area has focused on the development of delivery systems for peptides and protein drugs such as insulin and glucagon-like peptide-1 (GLP-1) agonists. $^{26,27}$ Although food protein hydrolysates and peptides have been successfully encapsulated using different carrier systems, including protein-, polysaccharide- and lipid-based carriers, further studies on the biostability and bioavailability of the encapsulated peptides are needed. ${ }^{28}$ To the authors' knowledge, the use of nanoparticles to encapsulate DPP-IV inhibitory peptides has not been explored yet. Therefore, further research into the application of nano-delivery systems to improve the bioavailability of these bioactive molecules is warranted.

\section{Conclusions}

Findings from the present research showed that milk proteinderived DPP-IV inhibitors are susceptible to enzymatic hydro- lysis by intestinal brush border membrane peptidases and have low permeability. Although the breakdown of bioactive peptides by intestinal enzymes could potentially lead to the generation of smaller more potent and/or more easily absorbed molecules, most of the degradation products identified in this study demonstrated lower inhibition of DPP-IV than the precursor peptides. Consequently, the peptide mixtures able to cross the Caco-2 cell monolayer showed a weaker inhibitory effect than the original intact peptides. This finding suggests that the apparent effectiveness of DPP-IV inhibitory peptides may be reduced in vivo and highlights the need to consider their bioavailability when assessing their potential as functional food ingredients for the management of glycemic regulation.

\section{Acknowledgements}

This research was financially supported by a Discovery Grant from the Natural Sciences and Engineering Research Council of Canada awarded to Eunice Li-Chan (NSERC council grant no. 121822-11).

\section{References}

1 T. D. Filippatos, V. G. Athyros and M. S. Elisaf, The pharmacokinetic considerations and adverse effects of DPP-4 inhibitors, Expert Opin. Drug Metab. Toxicol., 2014, 10, 787-812.

2 C. F. Deacon and H. E. Lebovitz, Comparative review of dipeptidyl peptidase-4 inhibitors and sulphonylureas, Diabetes, Obes. Metab., 2016, 18, 333-347.

3 I. M. E. Lacroix and E. C. Y. Li-Chan, Food-derived dipeptidyl-peptidase IV inhibitors as a potential approach for glycemic regulation-Current knowledge and future research considerations, Trends Food Sci. Technol., 2016, 54, 1-16.

4 O. Power, A. B. Nongonierma, P. Jakeman and R. J. FitzGerald, Food protein hydrolysates as a source of dipeptidyl peptidase IV inhibitory peptides for the management of type 2 diabetes, Proc. Nutr. Soc., 2014, 73, 34-46.

5 C. F. Deacon, Circulation and degradation of GIP and GLP-1, Horm. Metab. Res., 2004, 36, 761-765.

6 M. J. Dailey and T. H. Moran, Glucagon-like peptide 1 and appetite, Trends Endocrinol. Metab., 2013, 24, 85-91.

7 W. M. Miner-Williams, B. R. Stevens and P. J. Morghan, Are intact peptides absorbed from the healthy gut in the adult human?, Nutr. Res. Rev., 2014, 27, 308-329.

8 I. M. E. Lacroix and E. C. Y. Li-Chan, Dipeptidyl peptidaseIV inhibitory activity of dairy protein hydrolysates, Int. Dairy J., 2012, 25, 97-102.

9 I. M. E. Lacroix and E. C. Y. Li-Chan, Comparison of the susceptibility of porcine and human dipeptidyl-peptidase IV to inhibition by protein-derived peptides, Peptides, 2015, 69, 19-25. 
10 H. Tada, O. Shiho, K.-I. Kuroshima, M. Koyama and K. Tsukamoto, An improved colorimetric assay for interleukin 2, J. Immunol. Methods, 1986, 93, 157-165.

11 I. M. E. Lacroix and E. C. Y. Li-Chan, Isolation and characterization of peptides with dipeptidyl peptidase-IV inhibitory activity from pepsin-treated bovine whey proteins, Peptides, 2014, 54, 39-48.

12 M. Segura-Campos, L. Chel-Guerrero, D. Betancur-Ancona and V. M. Hernandez-Escalante, Bioavailability of bioactive peptides, Food Rev. Int., 2011, 27, 213-226.

13 G. Picariello, G. Iacomino, G. Mamone, P. Ferranti, O. Fierro, C. Gianfrani, A. Di Luccia and F. Addeo, Transport across Caco-2 monolayers of peptides arising from in vitro digestion of bovine milk proteins, Food Chem., 2013, 139, 203-212.

14 S. Howell, A. J. Kenny and A. J. Turner, A survey of membrane peptidases in two human colonic cell lines, Caco-2 and HT-29, Biochem. J., 1992, 284, 595-601.

15 M. Engel, T. Hoffmann, L. Wagner, M. Wermann, U. Heiser, R. Kiefersauer, R. Huber, W. Bode, H.-U. Demuth and H. Brandstetter, The crystal structure of dipeptidyl peptidase IV (CD26) reveals its functional regulation and enzymatic mechanism, Proc. Natl. Acad. Sci. U. S. A., 2003, 100, 5063-5068.

16 J. Rahfeld, M. Schierhorn, B. Hartrodt, K. Neubert and J. Heins, Are diprotin A (Ile-Pro-Ile) and diprotin B (Val-ProLeu) inhibitors or substrates of dipeptidyl peptidase IV?, Biochim. Biophys. Acta, 1991, 1076, 314-316.

17 A. B. Nongonierma and R. J. FitzGerald, Susceptibility of milk protein-derived peptides to dipeptidyl peptidase IV (DPP-IV) hydrolysis, Food Chem., 2014, 145, 845852.

18 V. P. Dia, S. Torres, B. O. De Lumen, J. W. Jr. Erdman and E. G. de Mejia, Presence of lunasin in plasma of men after soy protein consumption, J. Agric. Food Chem., 2009, 57, 1260-1266.

19 L. Ding, L. Wang, Y. Zhang and J. Liu, Transport of antihypertensive peptide RVPSL, ovotransferrin 328-332, in human intestinal Caco-2 cell monolayers, J. Agric. Food Chem., 2015, 63, 8143-8150.

20 L. Ding, Y. Zhang, Y. Jiang, L. Wang, B. Liu and J. Liu, Transport of egg white ACE-inhibitory peptide, Gln-Ile-GlyLeu-Phe, in human intestinal Caco-2 cell monolayers with cytoprotective effect, J. Agric. Food Chem., 2014, 62, 31773182.

21 G. M. Pauletti, F. W. Okumu and R. T. Borchardt, Effect of size and charge on the passive diffusion of peptides across Caco-2 cell monolayers via the paracellular pathway, Pharm. Res., 1997, 14, 164-168.

22 A. B. Nongonierma, C. Mooney, D. C. Shields and R. J. FitzGerald, Inhibition of dipeptidyl peptidase IV and xanthine oxidase by amino acids and dipeptides, Food Chem., 2013, 141, 644-653.

23 I. M. E. Lacroix and E. C. Y. Li-Chan, Investigation of the putative associations between dairy consumption and incidence of type 1 and type 2 diabetes, Crit. Rev. Food Sci. Nutr., 2014, 54, 411-432.

24 G. Picariello, P. Ferranti and F. Addeo, Use of brush border membrane vesicles to simulate the human intestinal digestion, Food Res. Int., 2016, 88, 327-335.

25 A. C. Lemes, L. Sala, J. da Costa Ores, A. R. C. Braga, M. B. Egea and K. F. Fernandes, A review of the latest advances in encrypted bioactive peptides from protein-rich waste, Int. J. Mol. Sci., 2016, 17, 950.

26 B. F. Choonara, Y. E. Choonara, P. Kumar, D. Bijukumar, L. C. du Toit and V. Pillay, A review of advanced oral drug delivery technologies facilitating the protection and absorption of protein and peptide molecules, Biotechnol. Adv., 2014, 32, 1269-1282.

27 P. Fonte, F. Araújo, C. Silva, C. Pereira, S. Reis, H. A. Santos and B. Sarmento, Polymer-based nanoparticles for oral insulin delivery: Revisited approaches, Biotechnol. Adv., 2015, 33, 1342-1354.

28 A. Mohan, S. R. C. K. Rajendran, Q. S. He, L. Bazinet and C. C. Udenigwe, Encapsulation of food protein hydrolysates and peptides: a review, $R S C A d v ., 2015$, 5, 79270-79278. 